\title{
Differential anticancer effect of fermented squid jeotgal due to varying concentrations of soymilk additive
}

\author{
Fahima Akther ${ }^{1} \cdot$ Jinhua Cheng ${ }^{2} \cdot$ Seung Hwan Yang ${ }^{1} \cdot$ Gyuhwa Chung $^{1}$ if
}

Received: 9 March 2017 / Accepted: 18 April 2017 / Published Online: 30 June 2017

(C) The Korean Society for Applied Biological Chemistry 2017

\begin{abstract}
Fermentation plays a vital role in the nutritional enrichment of food. Korea has a long tradition of adding fermented food to the daily diet and jeotgal is one of the common fermented and salted foods in Korean cuisine. In our study, we added soymilk as an additive to squid jeotgal to improve its functionality. We mixed different concentrations of soymilk $(2,5$, and $10 \mathrm{mg} / \mathrm{g})$ with squid jeotgal samples, fermented them for one week, and then tested their antioxidant and anticancer activities to compare with those of squid jeotgal samples without soymilk additive. To investigate the anticancer characteristics, glutathione-S-transferase (GST)-pi enzyme assay was used. To test the antioxidant activities, various assays were performed, including 2,2-diphenyl-1-picryl hydrazyl free radical scavenging activity, 2,2-azino-bis(3-ethylbenzothiazoline-6-sulfonic acid) diammonium saltradical cation scavenging assay, and reducing power assay. Samples fermented with a small amount of soymilk showed excellent anticancer activity. The addition of only $2 \mathrm{mg} / \mathrm{g}$ of soymilk to squid jeotgal inhibited the activity of GST-pi by almost $50 \%$ when compared with the sample with no addition. Moreover, no undesirable bitterness or astringency was noticed. Our results could help to improve the current food status of squid jeotgal and it could be used to reduce the risk of chronic disease along with its basic nutritional function.
\end{abstract}

Keywords Anticancer ' Fermentation ' Functional food . Glutathione-S-transferase-pi inhibition activity $\cdot$ Soymilk $\cdot$ Squid jeotgal

Gyuhwa Chung $(\triangle)$

E-mail: chung@chonnam.ac.kr

${ }^{1}$ Department of Biomedical and Electronic Engineering, Chonnam National University, Yeosu, Republic of Korea

${ }^{2}$ Division of Bioscience and Bioinformatics, College of Natural Science, Myongji University, Cheoin-gu, Yongin, Gyeonggi, Republic of Korea

This is an Open Access article distributed under the terms of the Creative Commons Attribution Non-Commercial License (http://creativecommons. org/licenses/by-nc/3.0/) which permits unrestricted non-commercial use, distribution, and reproduction in any medium, provided the original work is properly cited.

\section{Introduction}

Fermentation is one of the oldest techniques for food preservation and can increase the shelf life, nutritional and organoleptic qualities of food. In Southeast Asia, fermented and salted foods have been traditionally used for a long time. Fermented and salted seafood in Korean cuisine is known as jeotgal. Jeotgal can be processed using the whole meat and/or internal or specific parts of shrimp, fish, shellfish, oyster, crabs, squid, and octopus, where fermentation and salting inhibit the spoilage, autolysis, and decomposition of the main ingredients by microbial activity (Lee et al. 1993). Along with its taste and traditional use, jeotgal has attracted the attention of researchers because of its great nutritional value, together with its health benefits: including appetite, digestion, and promotion of beneficial microorganisms. In recent studies, researchers have focused on the safety and the functionality of jeotgal, such as supplying amino acids, antioxidants, antitumorigenics, antidiabetics, growth promoters, body fat reduction, and immune stimulation (Koo et al. 2016).

The health functions of jeotgal increase with the conversion of phytochemicals and with the increase in functional by-products of the fermentation process (Koo et al. 2016). In this study, we attempted to improve the functions of fermented squid jeotgal by adding soymilk. Soybean and soy foods have been consumed by Asians as a source of high quality proteins for centuries. Asians consume 30-50 times (30-50 mg/day) more soy products than Americans ( $<1 \mathrm{mg} /$ day), and thus have lower incidence of death rates due to hormone-dependent cancers, such as breast and prostate cancers (Messina and Virginia 2010). Kerwin (2004) identified that anticancer activities of soy saponins and isoflavones had direct effect on cancer cells.Moreover, soy isoflavones contain 12 different isoforms, with genistein as the major component, which have been reported to have antiangiogenic and antioxidant activities (Lee et al. 2012).

In the present study, we attempted to increase the health benefits of fermented squid jeotgal by adding soymilk at different concentrations, and analyzed its anticancer and antioxidant 
activities. We used Glutathione-S-transferase (GST)-pi enzyme assay to investigate the anticancer characteristics. For the antioxidant activities, a series of assays were performed: 2,2-diphenyl-1-picryl hydrazyl (DPPH) free radical scavenging activity assay, 2,2-azinobis (3-ethylbenzothiazoline-6-sulfonic acid) diammonium salt (ABTS) radical cation scavenging assay,andreducing power assay.

\section{Materials and Methods}

\section{Reagents}

Ethanol, Dimethyl sulfoxide (DMSO), methanol, Acetone, ABTS, potassium persulfate, ascorbic acid, DPPH, $0.2 \mathrm{M}$ sodium phosphate buffer ( $\mathrm{pH}$ 6.6), trichloroacetic acid, ferric chloride hexahydrate, potassium ferrocyanide, acetone, reduced glutathione, 1-chloro2,4-dinitrobenzene (CDNB), GST- pi (from human placenta), and $0.25 \mathrm{M}$ potassium phosphate buffer $(\mathrm{pH}$ 7.2) were used. All chemicals and reagents used in the study were of analytical grade and were purchased from Sigma-Aldrich (St. Louis, MO, USA).

\section{Extraction of soymilk powder}

Wild soybeans were collected from Chung's Wild Legume Germplasm Collection, Chonnam National University, Yeosu campus, South Korea. Wild soybeans were soaked in water at a ratio of $1: 3$ (soybean : water) (w/v) for $12 \mathrm{~h}$ at room temperature $\left(25^{\circ} \mathrm{C}\right)$. The mixture was then blended by using a food processor and the extract was then filtered by cheese cloth. At $-80{ }^{\circ} \mathrm{C}$, extraction was freeze dried to collect soy milk powder.

\section{Squid jeotgal sample preparation}

Squid jeotgal samples were prepared in the laboratory, using fresh small squids that were brought from Yeosu, South Korea. Seasonings, containing hot pepper flakes, salt and different types of grains were supplied by Greenmin Food Co., Korea, Yeosu and also followed their company procedure to prepare our jeotgal samples. Fresh squids were cut into small pieces and washed thoroughly. Then, $75 \mathrm{~g}$ of squid was mixed with $25 \mathrm{~g}$ of seasonings.

\section{Squid samples fermented with soymilk}

Final samples were prepared by adding soymilk at different concentrations $(2,5$, and $10 \mathrm{mg} / \mathrm{g})$ to the squid jeotgal. The samples were fermented for 1 week before their activities were checked.

\section{Preparation of soluble fraction}

A $5 \mathrm{~g}$ sample of fermented paste was added to $40-50 \mathrm{~mL}$ of solvent (70\% ethanol: 5\% DMSO: $25 \%$ water) and stirred for $1 \mathrm{~h}$ at $25{ }^{\circ} \mathrm{C}$. The mixture was centrifuged at $5,000 \times \mathrm{g}$ for $10 \mathrm{~min}$ using an Avanti TMJ-25I refrigerated centrifuge. The supernatant was used for further analysis.

\section{GST-pi enzyme inhibition assay}

The GST-pi activity was measured using a photometric assay according to Müller et al. (2008) with some modifications. In a 96-well plate, $50 \mu \mathrm{L}$ of extract was added in the blank and test wells. $50 \mu \mathrm{L}$ of CDNB solution was added to each well and $10 \mu \mathrm{L}$ of GST-pi enzyme was added to the test wells while $10 \mu \mathrm{L}$ of buffer was added to blank wells instead of the enzyme. The mixture was incubated at $37{ }^{\circ} \mathrm{C}$ for $5 \mathrm{~min}$. Thereafter, $50 \mu \mathrm{L}$ of reduced glutathione solution was added to each well and the plate was read immediately using a microplate reader at $340 \mathrm{~nm}$ at 37 ${ }^{\circ} \mathrm{C}$ and for five kinetic cycles. A control was run simultaneously by using $70 \%$ ethanol instead of extract along with the test samples. Blank values were subtracted from the corresponding test values. Lower absorbance indicated lower GST-pi activity, suggesting a higher anticancer property.

\section{DPPH free radical scavenging activity}

The DPPH scavenging activity was determined by the method of Gyamfi et al. (1999) with some modifications. Extract $(20 \mu \mathrm{L})$ was mixed with $200 \mu \mathrm{L}$ of DPPH methanolic solution $(100 \mu \mathrm{M})$. The mixture was mixed vigorously and kept at RT $\left(25^{\circ} \mathrm{C}\right)$ for 30 min in the dark. The absorbance of the resulting solution was measured at $517 \mathrm{~nm}$ against a blank, which was prepared in the same manner, except that $70 \%$ ethanol was used instead of the sample. Ascorbic acid was used as a positive control. The scavenging activity was measured by the following formula:

$$
\mathrm{DPPH}^{*} \text { scavenging activity }=\left(1-\mathrm{A}_{\text {sample }} / \mathrm{A}_{\text {control }}\right) \times 100 \%
$$

\section{ABTS radical cation scavenging assay}

ABTS radical scavenging activity was determined by an ABTS assay using the method of $\mathrm{Re}$ et al. (1999) with a slight modification. The stock solutions included $7 \mathrm{mM}$ ABTS solution and $2.45 \mathrm{mM}$ potassium persulfate solution. The working solution was prepared by mixing the two stock solutions in equal quantities and allowing them to react for $12-16 \mathrm{~h}$ at room temperature in the dark. The solution was then diluted by adding distilled water to obtain an $\mathrm{OD}_{734}=0.7$, measured using a UV-spectrophotometer. Fresh ABTS solution was prepared for each assay. The sample (10 $\mu \mathrm{L}$ ) was mixed with $1 \mathrm{~mL}$ of working ABTS solution and the mixture was left at RT for 5-10 min. Absorbance at $734 \mathrm{~nm}$ was then measured by using the spectrophotometer against a blank. Blank was prepared in the same manner, except that $70 \%$ ethanol was used instead of the sample. Ascorbic acid was used as a positive control.

The scavenging activity was expressed by the following formula:

$$
\text { ABTS* scavenging activity }=\left(1-\mathrm{A}_{\text {sample }} / \mathrm{A}_{\text {control }}\right) \times 100 \%
$$

\section{Reducing power assay}

Reducing power was determined according to Oyaizu (1986), modified slightly. Sample extract $(1 \mathrm{~mL})$ was mixed with $1 \mathrm{mLof}$ 


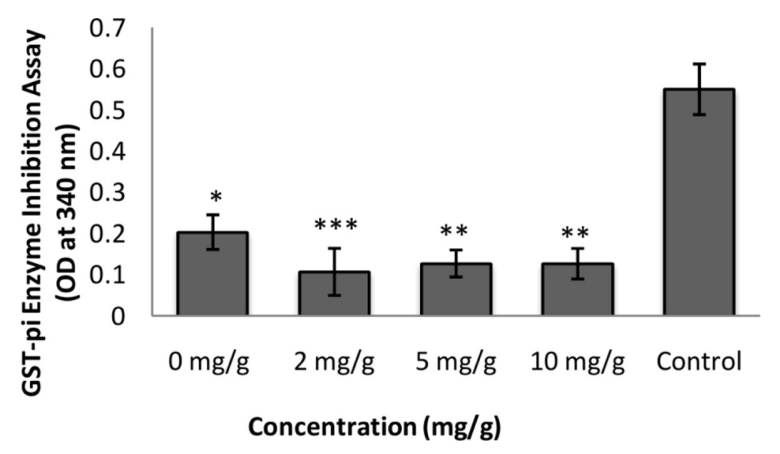

Fig. 1 Result of anticancer activity of fermented squid jeotgal samples with soy milk at various concentrations by GST-pi enzyme inhibition assay. Results represent the average of three replicates $(n=3)$. Error bars indicate the standard deviation $( \pm \mathrm{SD}) .70 \%$ ethanol instead of samples with GST-pi enzyme is used as control. Data points indicate with different number of $\left({ }^{*}\right)$ are significantly different from each other compare to control at $p \leq 0.05$

$200 \mathrm{mM}$ sodium phosphate buffer ( $\mathrm{pH} 6.6)$, and $1 \mathrm{~mL}$ of $1 \%(10$ $\mathrm{mg} / \mathrm{mL}$ ) potassium ferricyanide was added with the mixture. The mixture was incubated at $50{ }^{\circ} \mathrm{C}$ for $20 \mathrm{~min}$. After cooling, $1 \mathrm{mLof}$ $10 \%$ trichloroacetic acid (w/v) was added, and the mixture was centrifuged at $6,500 \mathrm{rpm}$ for $10 \mathrm{~min}$. A $2 \mathrm{~mL}$ portion of the supernatant was mixed with $2 \mathrm{~mL}$ of distilled water and $400 \mu \mathrm{L}$ of $0.1 \%$ of ferric chloride. The absorbance of the sample was measured at $700 \mathrm{~nm}$. Ascorbic acid was used as the reference standard. A higher absorbance indicated higher reducing power.

\section{Statistical analysis of data}

All tests were performed at least three times. Means were compared using analysis of variance (ANOVA), and significant differences in the tests were analyzed by SPSS ver. 22 (IBM SPSS statistics, New York, NY, USA). The results are expressed as the mean \pm standard deviation (SD). A difference was considered statistically at $p \leq 0.05$.

\section{Results}

\section{GST-pi enzyme inhibition assay}

The addition of a small amount of soymilk to squid jeotgal showed excellent anticancer activity. Compared with the control, the addition of soymilk in all concentrations, showed significant decreased in absorbance. The control absorbance was $\mathrm{OD}_{340}=$ $0.5508 \pm 0.0614$. The addition of only $2 \mathrm{mg} / \mathrm{g}$ of soymilk to squid jeotgal inhibited the GST-pi enzyme activity by almost $50 \%$. At high concentrations, activity slightly reduced. Addition of both $5 \mathrm{mg} / \mathrm{g}$ and $10 \mathrm{mg} / \mathrm{g}$ soymilk powder inhibited the enzyme activity by $37 \%$. Absorbance for samples fermented with no addition, 2, 5 , and $10 \mathrm{mg} / \mathrm{g}$ were $0.204 \pm 0.0421,0.108 \pm 0.0571,0.128 \pm 0.0327$,
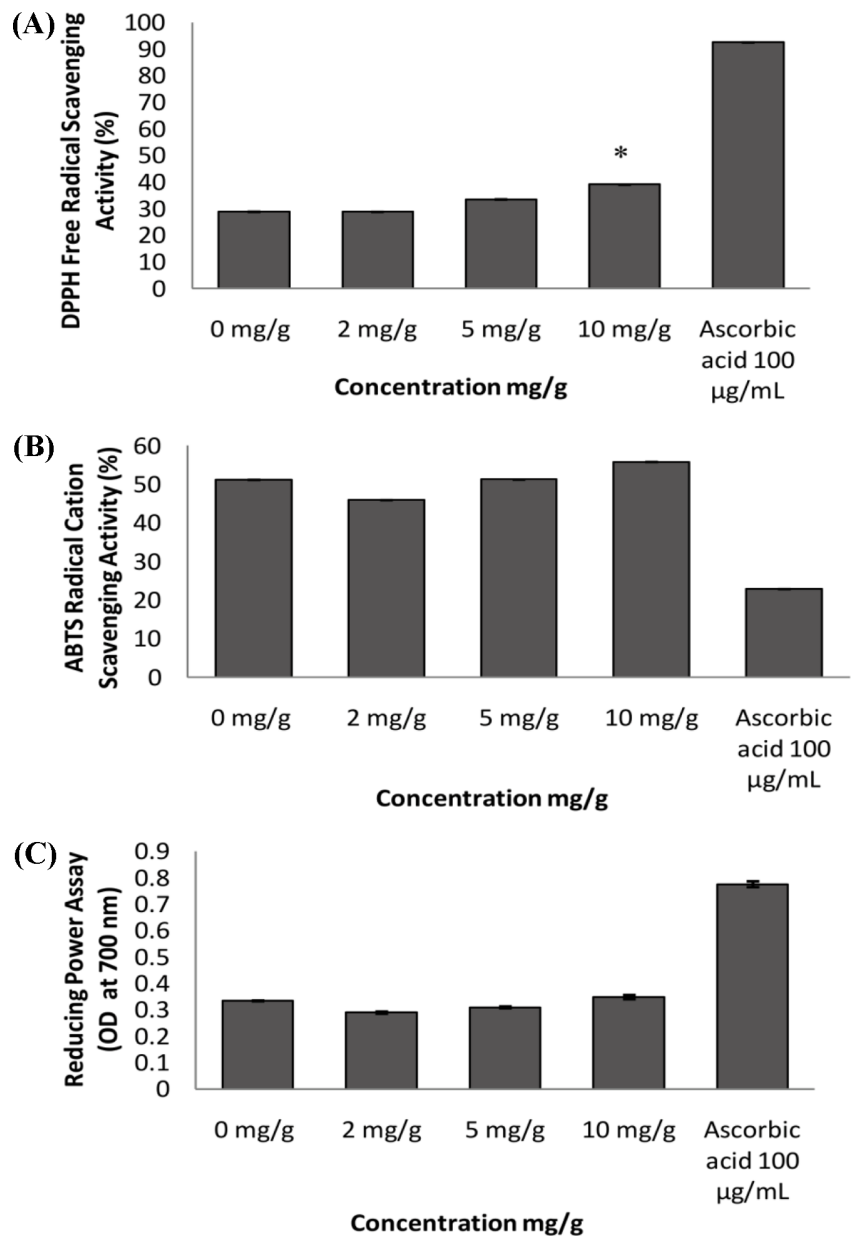

Fig. 2 Results of antioxidant assays of squid jeotgal samples fermented with soy milk. (A) DPPH free radical scavenging activity, (B) ABTS radical cation scavenging assay. (C) Reducing power assay. Results represent the average of three replicates $(n=3)$. Error bars indicate the standard deviation $( \pm \mathrm{SD})$. Ascorbic acid is used as positive control in all three assays. Data point indicates with $(*)$ is significantly different from sample without soy milk addition at $p \leq 0.05$

and $0.127 \pm 0.0372$, respectively (Fig. 1).

\section{Antioxidant assays}

In all three assays (DPPH free radical scavenging activity, ABTS radical cation scavenging assay, and Reducing power assay), samples fermented with low concentration of soymilk ( 2 or $5 \mathrm{mg}$ / g) showed reduced antioxidant activity, while those fermented with high concentration $(10 \mathrm{mg} / \mathrm{g})$ showed a slight and nonsignificant increasein activity when compared with the activity of the fermented sample without soymilk. Only in DPPH free radical scavenging activity, sample containing $10 \mathrm{mg} / \mathrm{g}$, showed significant increase in activity compared to sample without soy milk additive $(p \leq 0.05)$ (Fig. 2). 


\section{Discussion}

Fermentation process enriches foods with essential amino acids, vitamins, and bioactive compounds. The addition of bioactive grains and other sub ingredients, such as garlic and hot pepper in Kajami-sikhae (flat fish), resulted strong anticancer activity (Shoji et al. 1997). Carcinogenicity and drug resistance in cancer have become the major focus of researchers in recent years. Phytochemicals of soybean, including saponins and isoflavones, are considered good sources of anticancer activity (Yoon et al. 2005). Recent studies revealed GST-pi enzymes are frequently over expressed in neoplastic tissues and have been considered as important markers of a number of tumors, such as lung, ovarian, breast, and gastric carcinoma (Ren et al. 2015). Thus, a component that inhibits GSTpi enzyme activity could be considered to possess good anticancer activity. In our study, the addition of a small amount of soymilk to squid jeotgal caused significant inhibition of GST-pi enzyme activity.

However, the antioxidant assays demonstrated that the squid jeotgal fermented with soymilk does not have a powerful antioxidant activity. Moreover, the activities slightly reduced when compared with the sample without soymilk. The mechanism of the reduction of antioxidant activities by soymilk is unclear. It can be hypothesized that fermentation breaks down complex compounds into simpler components, where certain proteins produced reactive oxygen species (ROS) that might reduce the antioxidant activity.

ROS are known to increase oxidative stress, which could inhibit tumor growth and lead to apoptosis of cancer cells. Indeed, the main characteristic of anticancer agents is their cytotoxic effect on tumor cells (Armstrong et al. 2002; Barrera 2012). This may be one of the reasons why our samples showed good anticancer activity but no antioxidant effect. Moreover, no undesirable bitter taste was noticed in the samples which could enhance the chance to make our samples as an acceptable food item to the consumers. Further analysis is needed to identify the actual mechanism underlying our hypothesis. Furthermore, the study should be extended to investigate a long-term fermentation process, to increase our understanding of how the bioactivities vary according to the fermentation period and concentration.
Acknowledgments The work (Grants No. C0276151) was supported by Business for Cooperative R\&D between Industry, Academy, and Research Institute funded Korea Small and Medium Business Administration in 2015.

\section{References}

Armstrong JS, Steinauer KK, Homung B, Irish JM, Lecane P, Birrell GW, Peehl DM, Knox SJ (2002) Role of glutathione depletion and reactive oxygen species generation in apoptotic signaling in a human B lymphoma cell line. Cell Death Differ 9: 252-263

Barrera G (2012) Oxidative stress and lipid peroxidation products in cancer progression and therapy. ISRN Oncoldio: org/10.5402/2012/137289

Gyamfi MA, Yonamine M, Aniya Y (1999) Free-radical scavenging action of medicinal herbs from Ghana: Thonningia sanguine on experimentallyinduced liver injuries. Gen Pharmacol 32: 661-667

Kerwin SM (2004) Soy saponins and the anticancer effects of soybeans and soy-based foods.Curr Med Chem Anticancer Agents 4: 263-272

Koo OK, Lee SJ, Chung KR, Jang DJ, Yang HJ, Kwon DY (2016) Korean traditional fermented fish products: jeotgal. J of Ethnic Foods 3: 107-116

Lee JY, Kim HS, Song YS (2012) Genistein as a potential anticancer agent against ovarian cancer. J Tradit Complement Med 2: 96-104

Lee SH, Lee HJ, Kang KO (1993) Studies on the origin and nutrition of jeotgal (fermented fish products). Anseong Nat Polytech Univ Rep 25: $175-195$

Messina M, Virginia M (2010) The role of soy in vegetarian diets. Nutrients 2: $855-888$

Müller J, Sidler D, Nachbur U, Wastling J, Brunner T, Hemphill A (2008) Thiazolides inhibit growth and induce glutathione-S-transferase Pi (GSTP1)-dependent cell death in human colon cancer cells. Int J Cancer 8: $1797-1806$

Oyaizu M (1986) Studies on products on browning reaction prepared from glucose amine. Jpn J Nutr 44: 307-315

Re R, Pellegrini N, Proteggente A, Pannala A, Yang M, Rice-Evans C (1999) Antioxidant activity applying an improved ABTS radical cation decolorization assay. Free Radic Bio Med 26: 1231-1237

Ren S, Zhou F, Xu C, Li B (2015) Simple method for visual detection of glutathione $S$-transferase activity and inhibition using cysteamine-capped gold nanoparticles as colorimetric probes. Gold Bull 48: 147-152

Shoji F, Nobuyasu T, Takaki H, Hideki W (1997) Cancer prevention by organosulfur compounds from garlic and onion. J Cellular Biochem 27: 100-107

Yoon BL, Hyong JL, Chung HK, Soo BL, and Heon SS (2005) Soy Isoflavonesand Soyasaponins: Characteristics and Physiological Functions. Agric Chem Biotechnol 48: 49-57 